possible design changes needed to the probe, and how the size and surface of the target comet will affect the lander's descent plan.

Rosetta's planners currently seem to favour a spring 2004 launch that would allow targeting of the comet ChuryumovGerasimenko; other possible windows would allow visits to the comets Howell, Finlay, Schwassmann-Wachmann 2 and Wild-2. Launch dates for these options cannot be firmly defined until scientists at ESA's Operations Centre in Darmstadt, Germany, take ESTEC's proposals and work out the various possible trajectories to get the craft to its potential targets. But these targets might not be reachable until 2015 - a painful delay for those involved in a mission for which planning began in 1993.

Rosetta teams will meet on 13 February to consider possible solutions to the problem, before presenting them to ESA's Science Programme Committee on 26 February. But the crunch will come in May, when ESA will select one of the options - and decide how to pay for it. Southwood estimates that the delay will inflate the mission's E1-billion (US\$1-billion) price tag by a further E50 million-100 million.

ESA may ask its member states to make a one-off contribution to cover this, although with national space budgets under pressure, this may not be forthcoming (see previous page). That could force the agency to make cuts elsewhere in its science programme - possibly including the cancellation of Venus Express, ESA's planned 2005 mission to Venus.

\title{
Mozambique prime minister tipped for global health post
}

\section{Declan Butler, Paris}

An African official is emerging as the frontrunner to succeed Gro Harlem Brundtland as director-general of the World Health Organization (WHO) in May.

If he is elected, Mozambique's prime minister Pascoal Mocumbi will be the first African to head the WHO. The chances that Mocumbi will win a secret ballot of the WHO's 32-strong executive board to be held next week increased after his strongest African rival, former Senegalese health minister Awa Marie Coll-Seck, withdrew from the contest. Mocumbi says that he would resign from his current position if appointed to lead the Geneva-based organization.

Others shortlisted are Julio Frenk Mora, Mexico's health minister; Peter Piot, a former AIDS researcher who now heads the Joint UN Programme on HIV/AIDS (UNAIDS); Jong Wook Lee, a physician from South Korea, who heads the WHO's tuberculosis programme; and former Egyptian health minister Ismail Sallam. The World Health Assembly is expected to endorse the board's choice when it meets in Geneva in May.

The WHO is under strong pressure to end the political horse-trading that traditionally characterizes its elections. This time, The Lancet and the New York-based Rockefeller Foundation have organized a campaign to introduce greater openness into what they describe as the "secret and generally unaccountable process" of the election.

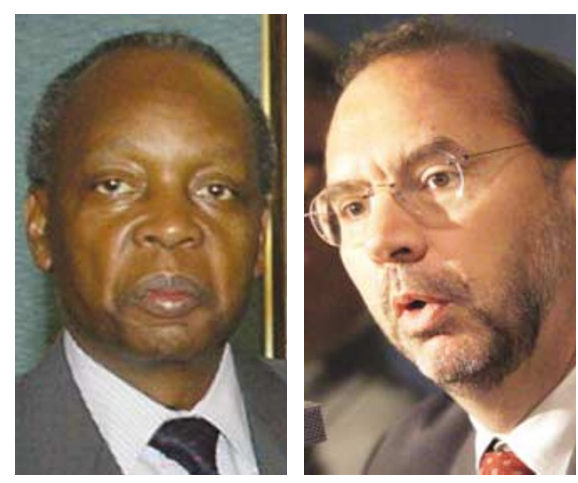

Pascoal Mocumbi (left) and Peter Piot are in the running to head the World Health Organization.

Critics of the election process say that it reflects the highly politicized workings of many international agencies during the cold war, and should be replaced by a more open and merit-based contest when the next director-general is elected in 2008.

Under pressure to fight an open campaign, candidates initially agreed to take part in a two-hour question-and-answer session on 19 January, set up by non-governmental organizations and the Interactive Health Network's World Health Channel, and broadcast live on the Internet. But several of the candidates pulled out of the session.

Each candidate has, however, taken up The Lancet's challenge to provide detailed responses on its website to ten questions about the WHO's future direction.

\section{Bushfires annihilate Australian observatory}

Carina Dennis, Sydney

One of Australia's premier observatories has been destroyed by bushfires that have raged for days in and around the nation's capital, Canberra. Flames engulfed Mount Stromlo

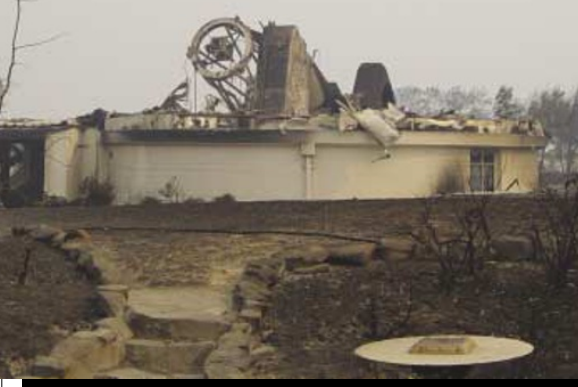

Gutted: the charred remains of Mount Stromlo Observatory - remarkably, some data survived.
Observatory, which lies at the western outskirts of the city, on 18 January, melting telescope housings, incinerating workshops and destroying precious archives.

"It looks like it has been firebombed," says Brian Schmidt, a research fellow at the Australian National University's astronomy school in Canberra, which operates the observatory. "All our active telescopes have been destroyed."

No astronomers were killed or injured in the fires - which caused four deaths and injured hundreds in the area - but several of their homes near the observatory were destroyed. Preliminary estimates value the observatory's losses at more than $\mathrm{A} \$ 20$ million (US\$12 million), although Schmidt thinks the final figure could be twice as much.

Many research projects have been cut short or temporarily halted by the fire, including a five-year programme led by
Schmidt to digitally map the southern sky.

The observatory's construction workshops were destroyed in the blaze, including those that were to be used for a A \$6.3-million contract to build an imager for the Gemini South Telescope in Chile. A A \$5-million near-infrared integral field spectrograph for the Gemini North Telescope in Hawaii, which was ready for shipment, was also damaged.

Historical records have been lost, including drawings of astronomical objects, some dating from the nineteenth century. But buildings containing computers and databases were spared. "Our current research data seem to be intact," says Schmidt.

The Australian National University has already given assurances that the observatory will be rebuilt, with resources and facilities made available to researchers to fulfil equipment contracts in the interim. 